An author may distribute only the final PDF version of an article at his or her discretion at any time after publication. The PDF may be posted on the author's website, placed in an institutional repository, or emailed by the author to interested colleagues. http://www.jdentaled.org

\title{
Brazilian Dental Students' Intentions and Motivations Towards Their Professional Career
}

\author{
Beatriz Ferraz dos Santos, M.Sc.; Belinda Nicolau, Ph.D.; Katia Muller, Ph.D.; \\ Christophe Bedos, Ph.D.; Angela Cristina Cilense Zuanon, Ph.D.
}

Abstract: Investigating career motivations and intentions of dental students provides a better understanding of their role in society and contributes to the debate on dental education and practices. This study describes the profile, career choice motivations, and career intentions of Brazilian dental students and evaluates factors related to these choices. A cross-sectional study was carried out among dental students from three Brazilian public universities ( $\mathrm{N}=915)$, with a response rate of 83.7 percent. Students $(\mathrm{N}=766)$ responded to a self-administered questionnaire about sociodemographic factors, reasons for choosing dentistry as a career, and future career intentions. Job conception was found to be the main reason for choosing dentistry as a profession. Most students intended to become specialists and work in both the public and private sectors simultaneously. Female students (OR 2.23, 95 percent $\mathrm{CI}=1.62-3.08$ ), low-income students (OR 1.86, 95 percent $\mathrm{CI}=1.10-3.13$ ), and students beginning their program (OR 1.87, 95 percent $\mathrm{CI}=1.22-2.85$ ) were more likely to work in the public and private sectors simultaneously than other types of students. This study suggests that choice of career and career plans are influenced by factors related to the students' characteristics and their conception of the profession. The opportunity to combine private and public dental practice may be viewed as a way to achieve income and job security.

Ms. Ferraz dos Santos is in the Department of Orthodontics and Pediatric Dentistry, Araraquara School of Dentistry, UNESPPaulista State University, Araraquara, Brazil; Dr. Nicolau is Associate Professor, INRS, Institut Armand-Frappier, Laval, Quebec, Canada; Dr. Muller is Research Associate, Faculty of Dentistry, McGill University, Montreal, Quebec, Canada; Dr. Bedos is Associate Professor, Faculty of Dentistry, McGill University, Montreal, Quebec, Canada; and Dr. Zuanon is Associate Professor, Department of Orthodontics and Pediatric Dentistry, Araraquara School of Dentistry, UNESP-Paulista State University, Araraquara, Brazil. Direct correspondence and requests for reprints to Ms. Beatriz Ferraz dos Santos, Department of Orthodontics and Pediatric Dentistry, Araraquara School of Dentistry, UNESP-Paulista State University, Rua Humaitá, 1680, Araraquara 14801-903, Brazil; beaferraz@yahoo.com.

Keywords: dental students, oral health care access, career choice, professional practice, oral health care workforce, Brazil

Submitted for publication 11/4/11; accepted 5/3/12

$\mathrm{T}$ The existence of a social gradient leading to oral health care inequities has sparked public health research aimed at identifying and understanding the primary causes of the problem. ${ }^{1,2}$ Differences in access to oral health care services ${ }^{3}$ are among the major contributing factors. While those in the higher socioeconomic strata around the world have abundant access to private or insured dental care, those in the lower strata cannot afford the high fees and are dependent solely on the public system. In addition, current characteristics of the dental workforce such as overspecialization and business orientation result in a lack of oral health providers with a broad understanding of the societies in which they work. ${ }^{4}$

To better understand this situation and, in the long term, find means for a change, many studies have investigated students' motivations for choosing a dental career and their future career intentions. ${ }^{5-14}$ Among the factors identified are the assurance of employment opportunities, conception of dentistry as a profession, influence of family members, and perception of dentistry as a profitable career. Considered together, previous studies have reported that students generally choose dentistry for personal fulfillment and for the high status of the professional. ${ }^{5-7,12,15}$ Rarely do altruism and empathy towards the population's oral health status explain their career choices. Individual background and experiences, personal values, and beliefs ${ }^{16}$ as well as socioeconomic factors thus seem to have an impact on the decision to study dentistry. ${ }^{7,13,14,17}$

The Ministry of Health in Brazil ${ }^{18,19}$ has recently adopted new policies to increase access to health care for disadvantaged populations. However, the success of these policies is largely dependent on the willingness of dental professionals to work in the public health service and with socially deprived patients, which in turn is directly related to the students' profiles and their future career intentions. 
In other words, the selection and training of dental students are critical stages that determine whether dental schools produce professionals tailored to the needs of the population or not. Although previous Brazilian studies ${ }^{5,8}$ have reported consistent results concerning dental students' professional career intentions, we hypothesized that recent changes in dental education and profession in this country might impact the students' career plans. The purpose of this study was to describe the profile, main career choice motivation, and future career intentions of the emerging dental workforce in Brazil. In addition, we evaluated whether students' sociodemographic background and the university where they were trained influenced their intentions to pursue a public services career.

\section{Methods}

In 2010, we carried out a cross-sectional survey aimed at evaluating dental students' perceptions of poverty, future career choices, and intentions. Three out of seven public dental schools in the state of São Paulo, Brazil, were selected as a convenience sample to be part of this survey. All students regularly enrolled in these schools in 2010 were invited to participate $(\mathrm{N}=915)$. The study was approved by the Ethics Committee of Araraquara Dental School, and all participants signed a consent form. Participation was voluntary and anonymous.

Dental schools in Brazil are divided into public (fifty-five) and private (148). Approximately 40,000 students are enrolled in these schools. The public dental schools are fully funded by the Brazilian government. The public schools included in this study are among the most renowned in Brazil, so admission to these universities is an extremely competitive process. To pass the entrance exam and be admitted, applicants need a strong secondary education, which is usually achieved in private and expensive secondary schools. Private universities, on the other hand, are not as renowned but have high tuition fees. The admission of students from lower income families is therefore limited in both types of dental schools.

The research instrument was a self-administered questionnaire. This survey was completed during regularly scheduled class sessions in an average time of ten minutes. The questionnaire, designed to maximize response rate and minimize missing data, consisted of twenty-one closed and open questions concerning sociodemographic factors, reasons for choosing dentistry as a career, and future career intentions. The latter included the type of practice intended after graduating (private, public, or both), the reasons for this choice, and intentions to pursue a specialist career. The questionnaire also included an open-ended question addressing dental students' reasons for choosing dentistry as a career. The questions were selected from previous similar studies ${ }^{5-8,10}$ and adapted to the Brazilian context. We conducted a pilot study among graduate dental students (four males and twenty females) to evaluate the questions' format and sequence; this led to minor modifications (e.g., to clarify the questions).

Data were analyzed using the statistical software program PASW Statistics version 18.0 (SPSS Inc., Chicago, IL, USA). Descriptive statistics were used to report percentages of respondents for selected sociodemographic variables and to describe aspects related to career choice. To evaluate differences in the students' responses, a Pearson's chi-square test was performed. A content analysis technique ${ }^{20}$ was used to categorize the reasons given by dental students for choosing dentistry as a career and the frequency with which each reason was cited. These categories were analyzed and tabulated. Associations between university training, sociodemographic factors, and students' intentions to work in the public system were evaluated using logistic regression analysis. Our dependent variable - intention to work in the public sector-was defined as intention to work only in the private sector against intentions to work in the public sector only or in both the public and private sectors. Statistical significance was based on probability values $\leq 0.05$.

\section{Results}

Out of 915 students enrolled in the participating schools, 766 participated in our survey, representing an overall response rate of 83.7 percent. The majority of participants were female $(n=518,67.6$ percent), and their age ranged from eighteen to thirty-four years $($ mean $=21, \mathrm{SD}=2)$ (Table 1). More than half of the participating students had parents with university degrees and high incomes.

These students' professional conception of dentistry (e.g., knowledge of dentistry, use of manual abilities, professional fulfillment, career flexibility, self-perceived vocation, and admiration for dentists/ dentistry) was their primary reason for choosing dentistry as a career (37.4 percent). Approximately 20 percent of the sample had chosen dentistry based 
Table 1. Distribution of selected variables according to university attended, by number and percentage

\begin{tabular}{|c|c|c|c|c|}
\hline Variable & University A ( $N=350)$ & University $B(N=253)$ & University C (N=163) & Total $(\mathrm{N}=766)$ \\
\hline \multicolumn{5}{|l|}{ Age } \\
\hline$\leq 20$ years & $132(37.7 \%)$ & $112(44.3 \%)$ & $79(48.5 \%)$ & $323(42.2 \%)$ \\
\hline 21-24 years & $195(55.7 \%)$ & $130(51.4 \%)$ & $78(47.9 \%)$ & $403(52.6 \%)$ \\
\hline$>24$ years & $23(6.6 \%)$ & $11(4.3 \%)$ & $6(3.7 \%)$ & $40(5.2 \%)$ \\
\hline \multicolumn{5}{|l|}{ Gender } \\
\hline Female & $252(72 \%)$ & $165(65.2 \%)$ & $101(62 \%)$ & $518(67.6 \%)$ \\
\hline Male & $98(28 \%)$ & $88(34.2 \%)$ & $62(38 \%)$ & $248(32.4 \%)$ \\
\hline \multicolumn{5}{|c|}{ Monthly family income } \\
\hline$R \$ 510-3060$ & $76(21.7 \%)$ & $69(27.3 \%)$ & $26(16 \%)$ & $171(22.3 \%)$ \\
\hline $\mathrm{R} \$ 3061-7650$ & $87(24.9 \%)$ & $69(27.3 \%)$ & $50(30.7 \%)$ & $206(26.9 \%)$ \\
\hline $\mathrm{R} \$ 7651-10200$ & $100(28.6 \%)$ & $77(30.4 \%)$ & $41(25.2 \%)$ & $218(28.5 \%)$ \\
\hline$>\mathrm{R} \$ 10200$ & $87(24.9 \%)$ & $38(15 \%)$ & $46(28.2 \%)$ & $171(22.3 \%)$ \\
\hline \multicolumn{5}{|c|}{ Mother's education } \\
\hline Elementary & $24(6.9 \%)$ & $19(7.5 \%)$ & $8(4.9 \%)$ & $51(6.7 \%)$ \\
\hline High school & $127(36.3 \%)$ & $86(34 \%)$ & $46(28.2 \%)$ & $259(33.8 \%)$ \\
\hline University & $199(56.9 \%)$ & $148(58.5 \%)$ & $109(66.9 \%)$ & $456(59.5 \%)$ \\
\hline \multicolumn{5}{|l|}{ Father's education } \\
\hline Elementary & $28(8 \%)$ & $27(10.7 \%)$ & $8(4.9 \%)$ & $63(8.2 \%)$ \\
\hline High school & $119(34 \%)$ & $76(30 \%)$ & $41(25.2 \%)$ & $236(30.8 \%)$ \\
\hline University & $203(58 \%)$ & $150(59.3 \%)$ & $114(69.9 \%)$ & $467(61 \%)$ \\
\hline \multicolumn{5}{|c|}{ Student's previous education } \\
\hline Public school & $42(12 \%)$ & $36(14.2 \%)$ & $16(9.8 \%)$ & $94(12.3 \%)$ \\
\hline Private school & $308(88 \%)$ & $217(85.8 \%)$ & $147(90.2 \%)$ & $672(87.7 \%)$ \\
\hline
\end{tabular}

a R $\$ 1.00$ Brazilian currency is equivalent to US\$0.58 and $0.44 €$ as of January 2012.

on the applied aspect of this health science (19.3 percent), followed by personal fulfillment (15.9 percent) and the influence of others (e.g., parents, family members, or friends who are dentists) (11.4 percent) (Table 2). Dentistry was not the first career choice for 3.2 percent of the respondents. Furthermore, only 4.3 percent of the total sample chose dentistry with the desire to contribute to people's health. The choice of a dental career based on financial reasons was given by 1.9 percent.

The majority of responding students reported an intention to work as a specialist (80.2 percent), whereas 11 percent intended to become general dentists and 8.9 percent intended to work in an academic setting (Table 3). More than half intended to work in both public services and private clinics (59.5 percent). Interestingly, 47 percent of the students at University $\mathrm{C}$ intended to work only in private clinics. The main reason given by those who planned to work in public services was job security (80.3 percent).

Odds ratios (OR) and 95 percent confidence intervals from logistic regression models were cal-
Table 2. Respondents' reasons for choosing dentistry as a career

\begin{tabular}{lc} 
Reason & $\mathrm{N}(\%)$ \\
\hline Professional conception & $287(37.4 \%)$ \\
Health science & $148(19.3 \%)$ \\
Personal fulfillment & $122(15.9 \%)$ \\
Influence of others & $88(11.4 \%)$ \\
I don't know & $48(6.2 \%)$ \\
Contribution to people's health & $33(4.3 \%)$ \\
Second option & $25(3.2 \%)$ \\
Financial motives & $15(1.9 \%)$ \\
Total & $766(100 \%)$ \\
\hline
\end{tabular}

culated to assess the associations between selected characteristics (e.g., sociodemographic, university attended by the students) and students' intentions to work in public services (whether in public services only or with a part-time private practice). The results showed that female students $(\mathrm{OR}=2.23,95$ percent $\mathrm{CI}=1.62-3.08)$ and those from low-income families $(\mathrm{OR}=1.86,95$ percent $\mathrm{CI}=1.10-3.13)$ were more 


\begin{tabular}{|c|c|c|c|c|}
\hline Variable & University A ( $N=350)$ & University $B(N=253)$ & University C (N=163) & Total $(\mathrm{N}=766)$ \\
\hline \multicolumn{5}{|l|}{ Professional goal } \\
\hline Generalist* & $35(10 \%)$ & $36(14.2 \%)$ & $13(8 \%)$ & $84(11 \%)$ \\
\hline Specialist & $267(76.3 \%)$ & $208(82.2 \%)$ & $139(85.3 \%)$ & $614(80.2 \%)$ \\
\hline Professor/research** & $48(13.7 \%)$ & $9(3.6 \%)$ & $11(6.7 \%)$ & $68(8.9 \%)$ \\
\hline \multicolumn{5}{|l|}{ Type of practice } \\
\hline Public services & $14(4 \%)$ & $5(2 \%)$ & $2(1.2 \%)$ & $21(2.7 \%)$ \\
\hline Private clinics & $122(34.9 \%)$ & $91(36 \%)$ & $76(46.6 \%)$ & $289(37.7 \%)$ \\
\hline Both & $214(61.1 \%)$ & $157(62.1 \%)$ & $85(52.1 \%)$ & $456(59.5 \%)$ \\
\hline \multicolumn{5}{|l|}{ Public service motivation } \\
\hline Job security & $192(84.2 \%)$ & $121(74.7 \%)$ & $70(80.5 \%)$ & $383(80.3 \%)$ \\
\hline Find likeable & $36(15.8 \%)$ & $41(25.3 \%)$ & $17(19.5 \%)$ & $94(19.7 \%)$ \\
\hline$* \mathrm{p}<0.05 ; * * \mathrm{p}<0.01$ & & & & \\
\hline
\end{tabular}

likely to report that they intended to work in public services when compared to male students and those from higher income groups. Similarly, first- and second-year dental students when compared to fourthyear dental students were more likely $(\mathrm{OR}=1.54,95$ percent $\mathrm{CI}=1.01-2.34$; $\mathrm{OR}=1.87,95$ percent $\mathrm{CI}=1.22$ 2.85 , respectively) to report an intention to work in public services. Finally, students at University C were less inclined to work in public services compared to students at University A $(\mathrm{OR}=0.59,95$ percent $\mathrm{CI}=0.40-0.89$ ) (Table 4).

\section{Discussion}

It has been previously recognized that family socioeconomic position plays an important role in students' educational attainment and access to higher education. ${ }^{21}$ This fact explains the homogeneity of our sample regarding social background, which was characterized by high family income, private previous education, and high parental education level. Similar to previous Brazilian studies, ${ }^{5,8}$ our results also showed that the number of female dental students in the sample exceeded that of men. These findings have been observed in other countries including the United States, ${ }^{13}$ Denmark, ${ }^{22}$ France, ${ }^{23}$ and the United Kingdom. ${ }^{14}$ The dental profession is attractive to women as it allows them to balance their personal and professional lives. In addition, women see dentistry as a way to work with others, as well as to achieve financial gain and professional prestige. . $^{13,24,25}$

Large differences may exist among dental students in attitudes about educational issues and career choices. We evaluated these dental students' motivations for choosing dentistry as a career and explored whether their future career intentions were influenced by their social background. Our findings regarding the reasons for choosing dentistry were in agreement with many previous studies. . $^{8,26-29}$ In general, the main reason for studying dentistry in this sample was related to the characteristics of the profession (38 percent). Other reasons selected were the applied health science aspect of dentistry, the influence of others, and personal fulfillment.

There is considerable evidence in the literature that financial reasons influence the career decision of dental students. ${ }^{15,22,30}$ However, in our study, financial motives were chosen least often as a motivation. These findings are likely to reflect the increased number of dentists in Brazil. Although the profession was known to be highly profitable two decades ago, there has been a substantial increase in the number of dental schools in Brazil, leading to an exponential increase in the dentist-population ratio. ${ }^{31}$ Consequently, dentists have been forced to lower their fees to competitive levels to attract patients in addition to having continuously fewer patients and lower incomes. Therefore, it is likely that current Brazilian dental students have a more realistic financial expectation of the profession and do not count on a future income level as high as it was a few decades ago. The fact that we explored the issue with an open-ended question further ensured a meaningful and honest answer from the students.

The present situation of the dental profession in Brazil, with lower incomes than previously for dentists, probably explains in part the wish of most dental students in our study to pursue further 
Table 4. Logistic regression model for students' intention to work in public services $(\mathrm{N}=766)$

\begin{tabular}{|c|c|c|c|c|}
\hline \multirow[b]{2}{*}{ Variable } & \multicolumn{2}{|c|}{ Type of Practice } & \multirow{2}{*}{$\begin{array}{l}\text { Unadjusted } \\
\text { OR }(95 \% \mathrm{Cl})\end{array}$} & \multirow{2}{*}{$\begin{array}{c}\text { Adjusted } \\
\text { OR }(95 \% \mathrm{Cl})\end{array}$} \\
\hline & Public Service \& Both & Private & & \\
\hline \multicolumn{5}{|l|}{ Gender } \\
\hline Male & $121(25.4 \%)$ & $127(43.9 \%)$ & Reference & \\
\hline Female & $356(74.6 \%)$ & $162(56.1 \%)$ & $2.30(1.69-3.14)$ & $2.23(1.62-3.08)$ \\
\hline \multicolumn{5}{|l|}{ Parents' education level } \\
\hline Both parents with elementary school & $20(4.2 \%)$ & $7(2.4 \%)$ & Reference & \\
\hline At least one of the parents with elementary & $37(7.6 \%)$ & $23(8 \%)$ & $0.56(0.20-1.53)$ & $0.61(0.21-1.73)$ \\
\hline No one with elementary & $420(88.1 \%)$ & $259(89.6 \%)$ & $0.56(0.23-1.36)$ & $0.62(0.25-1.55)$ \\
\hline \multicolumn{5}{|l|}{ Monthly family income ${ }^{a}$} \\
\hline $\mathrm{R} \$ 7000.00$ & $89(18.7 \%)$ & $80(27.7 \%)$ & Reference & \\
\hline $\mathrm{R} \$ 4561.58$ & $165(34.6 \%)$ & $109(37.7 \%)$ & $1.36(0.92-2.00)$ & $1.30(0.87-1.95)$ \\
\hline $\mathrm{R} \$ 2677.50$ & $146(30.6 \%)$ & $63(21.8 \%)$ & $2.08(1.36-3.17)$ & $2.03(1.31-3.16)$ \\
\hline $\mathrm{R} \$ 892.50$ & $77(16.1 \%)$ & $37(12.8 \%)$ & $1.87(1.14-3.06)$ & $1.86(1.10-3.13)$ \\
\hline \multicolumn{5}{|l|}{ University } \\
\hline University A & $228(47.8 \%)$ & $122(42.2 \%)$ & Reference & \\
\hline University B & $162(34 \%)$ & $91(31.5 \%)$ & $0.95(0.67-1.33)$ & $0.90(0.63-1.29)$ \\
\hline University C & $87(18.2 \%)$ & $76(26.3 \%)$ & $0.61(0.42-0.89)$ & $0.59(0.40-0.89)$ \\
\hline \multicolumn{5}{|l|}{ Student graduation year } \\
\hline 4rd year & $135(28.3 \%)$ & $102(35.3 \%)$ & Reference & \\
\hline $3 r d$ year & $89(18.7 \%)$ & $70(24.2 \%)$ & $0.96(0.64-1.44)$ & $1.00(0.65-1.53)$ \\
\hline 2nd year & $130(27.3 \%)$ & $56(19.4 \%)$ & $1.75(1.17-2.63)$ & $1.87(1.22-2.85)$ \\
\hline 1st year & $123(25.8 \%)$ & $61(21.1 \%)$ & $1.52(1.02-2.27)$ & $1.54(1.01-2.34)$ \\
\hline
\end{tabular}

specialty training after graduating, even at an early stage in their studies. ${ }^{26,32} \mathrm{~A}$ further explanation also supported by previous studies is the aspiration for higher earnings in combination with a higher professional status compared to general dentists. Given that the general population has high demands for basic oral treatments, the large numbers of students who plan to become specialists are inconsistent with the expectations and needs of society.

The majority of dental students surveyed intended to work both in public services and private sectors, and the main reason for planning to work in public services was job security ( 80.3 percent). In fact, Brazilian public health services usually pay modest salaries, but they provide job stability and other benefits in addition to allowing professionals to work in private practices. A relatively high percentage of dental students in our study (38 percent) stated a preference to work entirely in a private clinic, with only 3 percent planning to work exclusively within the public services. Our finding is consistent with that of similar studies in the United Kingdom ${ }^{10,25}$ and may be of considerable importance in predicting possible workforce patterns for the National Health System in the future.

The number of dentists employed in the Brazilian public health system has increased over the last few years. However, in São Paulo state, only 21 percent of dentists work in the public system, whether exclusively or concomitantly with a private clinic practice. ${ }^{31}$ It is worth commenting that, despite the fact that equity of access to care is a principle of the National Health System in Brazil, the distribution of dental care providers towards the most profitable markets (private services) creates a gap in access to care for the majority of the population that lives in poverty. Our findings concerning dental students' intentions support the existence of the inverse care law in dentistry, which states that "those with the least need of health care use the health services more, and more effectively, than do those with greatest need." ${ }^{33}$

Among the many reasons for the career aspirations of dental students, personal factors are perceived as key influences on future careers. The regression analysis model showed an important effect of socioeconomic position on the students' 
intentions to work in public services after graduating. Dental students from lower income groups are more inclined to work in public services. Considering the high prevalence of dental students from higher social backgrounds, this finding is at odds with the concern of the National Health System to provide public access to dental treatment. The problem may be slightly alleviated by the finding that female students, which constituted almost 70 percent of our sample, are more likely to work in public services than males. However, women dentists tend to have more career interruptions due to family care and therefore may contribute less to public care in the long term. ${ }^{34,35}$

In our study, intention to work in public services was also significantly affected by the university in which students were enrolled and their year of graduation. The differences found suggest that the educational philosophy and dental curriculum, which can vary among schools, may influence the students' future career intentions to work in public services. Although it was beyond the scope of this study to evaluate differences in curricula between schools, it is worth mentioning that recent guidelines have been set by the Brazilian Ministries of Education and Health ${ }^{18,19}$ with the aim of regulating the training and education of health professionals based on the principles of the National Health System. These principles emphasize universality, equity, and holistic health care for all citizens, and schools have been gradually adapting their curricula to comply with these principles. Interestingly, the schools included in the study had altered their curricula. Similar to other studies, year of graduation had a significant impact on students' intention to work in public services, with students in years 1 and 2 being more likely to respond positively than students in years 3 and 4 . Senior students may be more concerned about their future financial situation than junior students, which could influence their interest in working in private clinics. Furthermore, due to the structure of the educational system in Brazil, students apply to university studies at a very young age (eighteen) on average, many without ever having had to worry about personal finances. Indeed, dental students in the initial years of their studies tend to have a more idealistic view of the profession compared to final-year students, who build progressively over the years a positive view of private practice. ${ }^{36}$ However, research on the impact of years spent in dental school on the students' career intentions should be thoroughly explored using a cohort study design.
A few study limitations merit mention. First, the cross-sectional study design used did not allow us to establish whether the students' future career intentions changed over time. Second, the sample was recruited from three public dental universities located in São Paulo state, and the results cannot be generalized to all dental students in Brazil. However, our study had a high response rate and included renowned institutions and all Brazilian public universities located in the northwest region of São Paulo state. Therefore, it provides an overview of the future dental workforce trained by these institutions. Third, social correctness could have affected the students' responses. Although we cannot completely rule out the possibility of measurement errors, several measures of quality control were included to increase the validity of the data. The lead researcher (BF) gave a brief explanation of the study highlighting the importance of the students' expressing themselves as freely as possible. Also, the questionnaires were completely anonymous, and the students were assured of the confidentiality of the results. Finally, even if measurement error had occurred, we believe that our results are plausible and supported by the literature.

\section{Conclusion}

The findings of our study raise important issues about the students' professional motivations and highlight future career intentions of dental students that could contribute to more efficient planning of the dental workforce. This study also has implications for educators' responsibility to help students acquire and develop public service values and reinforce their altruistic motives to build the oral health care needed by the public. Our findings showed that improvements in dental curricula are needed to build an effective dental workforce responsive to public needs. This study also has implications for the importance of disadvantaged students' admission to dental schools based on their sensitivity to the value of working in public services. In addition, our findings highlight the importance of current efforts to improve and standardize a socially competent curriculum in Brazilian dental schools. However, it should be noted that there could be potential differences in knowledge and attitudes between students at the schools evaluated compared with other Brazilian dental schools. Future research should be encouraged to explore the factors that may be involved in dental 
students' career decisions. More studies are therefore needed to evaluate whether current dental curricula changes will impact the development of the dental workforce in Brazil.

\section{Acknowledgments}

We are indebted to all the universities for their assistance in providing access to the dental students. We also thank the students for their participation in this project. Drs. Bedos and Nicolau are recipients of salary awards from the Canadian Institutes of Health Research (CIHR) and Fonds de la recherche en santé du Québec (FRSQ). Dr. Ferraz-Santos was supported by a scholarship from Brazilian Agency Coordenação de Aperfeiçoamento de Pessoal de Nível Superior (CAPES).

\section{REFERENCES}

1. Locker D. Deprivation and oral health: a review. Community Dent Oral Epidemiol 2000;28(3):161-9.

2. Watt $\mathrm{R}$, Sheiham A. Inequalities in oral health: a review of the evidence and recommendations for action. Br Dent J 1999;187(1):6-12.

3. Guay AH. Access to dental care: the triad of essential factors in access-to-care programs. J Am Dent Assoc 2004;135(6):779-85.

4. Dal Poz MR, Quain EE, O’Neil M, McCaffery J, Elzinga $\mathrm{G}$, Martineau T. Addressing the health workforce crisis: towards a common approach. Hum Resour Health 2006;4:21.

5. Aguiar CM, Pessoa MA, Camara AC, Perrier RA, de Figueiredo JA. Factors involved in the choice of dentistry as an occupation by dental students in Pernambuco, Brazil. J Dent Educ 2009;73(12):1401-7.

6. Al-Bitar ZB, Sonbol HN, Al-Omari IK. Reasons for choosing dentistry as a career by Arab dental students. Eur J Dent Educ 2008;12(4):247-51.

7. Bernabe E, Icaza JL, Delgado-Angulo EK. Reasons for choosing dentistry as a career: a study involving male and female first-year students in Peru. Eur J Dent Educ 2006;10(4):236-41.

8. Freire MC, Jordao LM, de Paula FN, de Fatima NM, Queiroz MG, Leles CR. Motivation towards career choice of Brazilian freshman students in a fifteen-year period. J Dent Educ 2011;75(1):115-21.

9. Gallagher J, Clarke W, Wilson N. Understanding the motivation: a qualitative study of dental students' choice of professional career. Eur J Dent Educ 2008;12(2):89-98.

10. Gallagher JE, Patel R, Wilson NH. The emerging dental workforce: long-term career expectations and influences - a quantitative study of final year dental students' views on their long-term career from one London dental school. BMC Oral Health 2009;9:35.

11. Karibe H, Kawakami T, Suzuki A, Warita S, Ogata K, Aoyagi K, et al. Career choice and attitudes towards dental education amongst dental students in Japan and Sweden. Eur J Dent Educ 2009;13(2):80-6.
12. Khami MR, Murtomaa H, Jafarian M, Vehkalahti MM, Virtanen JI. Study motives and career choices of Iranian dental students. Med Princ Pract 2008;17(3):221-6.

13. Scarbecz M, Ross JA. Gender differences in first-year dental students' motivation to attend dental school. J Dent Educ 2002;66(8):952-61.

14. Stewart FM, Drummond JR, Carson L, Hoad RG. The future of the profession: a survey of dental school applicants. Br Dent J 2004;197(9):569-73.

15. Hallissey J, Hannigan A, Ray N. Reasons for choosing dentistry as a career: a survey of dental students attending a dental school in Ireland during 1998-99. Eur J Dent Educ 2000;4(2):77-81.

16. Blue CM, Lopez N. Towards building the oral health care workforce: who are the new dental therapists? J Dent Educ 2011;75(1):36-45.

17. Stewart FM, Drummond JR, Carson L, Hoad RG. A survey of dental school applicants' career intentions and the balance with family life. Br Dent J 2005;198(11):713-7.

18. Brasil Ministério da Educação PCCn10. Diretrizes Curriculares Nacionais dos Cursos de Graduação em Odontologia, 2001.

19. Brasil Ministério da Saúde Secretaria da Gestão do Trabalho e da Educação na Saúde. Programa Nacional de Reorientação da Formação Profissional em Saúde-Pró-Saúde, 2005.

20. Green J, Thorogood N. Qualitative methods for health research. London: Sage, 2004.

21. Gallagher JE, Niven V, Donaldson N, Wilson NH. Widening access? Characteristics of applicants to medical and dental schools, compared with UCAS. Br Dent J 2009;207(9):433-45.

22. Vigild M, Schwarz E. Characteristics and study motivation of Danish dental students in a longitudinal perspective. Eur J Dent Educ 2001;5(3):127-33.

23. Hennequin M, Tubert S, Devillers A, Muller M, Michailesco P, Peli JF, et al. Socioeconomic and schooling status of dental undergraduates from six French universities. Eur J Dent Educ 2002;6(3):95-103.

24. Butters JM, Winter PA. The effects of gender and race on practice pattern preferences of dental students. J Am Coll Dent 1999;66(3):39-46.

25. Stewart FM, Drummond JR, Carson L, Theaker ED. Senior dental students' career intentions, work-life balance, and retirement plans. Br Dent J 2007;203(5):257-63.

26. Hawley NJ, Ditmyer MM, Sandoval VA. Predental students' attitudes toward and perceptions of the dental profession. J Dent Educ 2008;72(12):1458-64.

27. Jover M, Doudoux D, Deveaux E. Representations of the dental surgery profession and the motivations given by second-year French students for applying for dental surgery. Eur J Dent Educ 2006;10(1):2-9.

28. Marino RJ, Morgan MV, Winning T, Thomson WM, Marshall RI, Gotjamanos T, et al. Sociodemographic backgrounds and career decisions of Australian and New Zealand dental students. J Dent Educ 2006;70(2):169-78.

29. Orenuga OO, da Costa OO. Characteristics and study motivation of clinical dental students in Nigerian universities. J Dent Educ 2006;70(9):996-1003.

30. Crossley ML, Mubarik A. A comparative investigation of dental and medical students' motivation towards career choice. Br Dent J 2002;193(8):471-3. 
31. Morita MC, Haddad AE, Araujo ME. Perfil atual e tendências do cirurgiáo-dentista brasileiro. Maringá: Dental Press International, 2010.

32. Lalloo R, Ayo-Yusuf OA, Yengopal V. Early-phase dental students' motivations and expectations concerning the study and profession of dentistry. SADJ 2008;63(4): 216-20.

33. Hart JT. The inverse care law. Lancet 1971;1(7696): 405-12.
34. Matthews RW, Scully C. Working patterns of male and female dentists in the UK. Br Dent J 1994;176(12):463-6.

35. Russell E, Leggate M. Dentists in general and community practice: a Scottish survey. Br Dent J 2002;193(6):333-7.

36. Skelly AM, Fleming GJ. Perceptions of a dental career among successful applicants for dentistry compared with those of fifth-year dental students. Prim Dent Care 2002;9(2):41-6. 